\title{
Estudo epidemiológico e clínico de afecções podais em bovinos de corte manejados extensivamente no sudeste do Pará ${ }^{1}$
}

\author{
José A.S. Silveira ${ }^{2 *}$, Natália S. Silva ${ }^{3}$, Tatiane T. Albernaz², Henrique A. Bomjardim², \\ Alessandra S.B. Reis ${ }^{2}$, Carlos M.C. Oliveira ${ }^{2}$, Marcos D. Duarte ${ }^{2}$ e José D. Barbosa ${ }^{2}$
}

\begin{abstract}
Silveira J.A.S., Silva N.S., Albernaz T.T., Bomjardim H.A., Belo Reis A.S., Oliveira C.M.C., Duarte M.D. \& Barbosa J.D. 2018. [Epidemiological and clinical study of foot diseases in beef cattle extensive management in southeastern Pará, Brazil.] Estudo epidemiológico e clínico de afecções podais em bovinos de corte manejados extensivamente no sudeste do Pará. Pesquisa Veterinária Brasileira 38(3):367-373. Faculdade de Medicina Veterinária, Instituto de Medicina Veterinária, Campus Castanhal, Universidade Federal do Pará, Rodovia BR-316 Km 61, Castanhal, PA 68741-740, Brazil. E-mail: jalcides@ufpa.br

The epidemiological study was conducted in 12 farms with the history of foot disease occurrence. Clinical examination of the affected cattle for the diagnosis of foot disease was performed only on nine of these farms. Multiple risk factors were found for digit injuries, as syringes floors paved with rocks, working chutes with iron fittings exposure, loading ramps covered with sharp stones and the lack of maintenance and structural errors. On each farm there was an inappropriate handling of cattle. On $91.7 \%$ of them $(11 / 12)$ existed pickets with trunks of trees and $66.7 \%$ (8/12) had areas of sloping relief with stones. Moreover, $16.7 \%$ (2/12) of the farms were in marsh areas and wetlands. Sodomy was reported for all farms. None of them adopted preventive measures related to foot problems. A total of 498 cattle, males and females, were examined. The hind limbs were the most affected in both, females and in males. In females 629 lesions were diagnosed. The septic pododermatitis was the most common, followed by claw deformities, pododermatitis in the paradigits and digital dermatitis. In males 285 injuries were diagnosed; the most common were septic pododermatitis, claw deformities and heel erosion. It was concluded that management errors associated with inadequate facilities were factors that contributed to the occurrence of foot diseases in beef cattle of the farms studied. The environmental characteristics favored the development of lesions; combined injuries were more prevalent than the simple ones diagnosed in cattle of all farms. Early diagnosis was not carried out in the field, what helped to increase the severity and the diversification of the foot problems.

INDEX TERMS: Epidemiology, foot diseases, bovine, Brazil, claudication, pododermatitis, cattle, Amazon region, clinics.
\end{abstract}

\footnotetext{
${ }^{1}$ Recebido em 8 de junho de 2016.

Aceito para publicação em 3 de maio de 2017.

Parte da tese de doutorado do primeiro autor, Programa de Pós-Graduação em Ciência Animal, Universidade Federal do Pará (UFPA), Rua Augusto Corrêa 1, Terra Firme, Belém, PA 66075-110, Brasil.

${ }^{2}$ Instituto de Medicina Veterinária, Faculdade de Medicina Veterinária, Campus de Castanhal, UFPA, Rodovia BR-316 Km 61, Castanhal, PA 68741-740, Brasil. *Autor para correspondência: jalcides@ufpa.br

${ }^{3}$ Universidade Federal Rural da Amazônia, Campus Paragominas, Rodovia PA-256, Bairro Nova Conquista, Paragominas, PA 68627-451, Brasil.
}

RESUMO.- Foram avaliados os fatores epidemiológicos e as afecções podais de bovinos de corte no estado do Pará em 12 propriedades. Em todas foi realizado o estudo epidemiológico e em nove o estudo epidemiológico e o exame clínico dos animais. Nos centros de manejo foram observados fatores favoráveis a traumatismos nos dígitos dos bovinos, como piso das seringas calçado com pedras, troncos com exposição de ferragens e rampas dos embarcadores com pisos de pedras pontiagudas, além da falta de manutenção e erros estruturais. Em todas as fazendas observou-se um manejo 
inadequado dos animais. Em 91,7\% das fazendas (11/12) havia piquetes com presença de troncos de árvores e $66,7 \%$ $(8 / 12)$ apresentavam áreas de relevo inclinado com presença de pedras. Em 16,7\% (2/12) das fazendas havia áreas de brejo com áreas alagadas. A sodomia foi relatada em todas as propriedades. Nenhuma fazenda adotava medidas profiláticas relacionadas às afecções podais. Foram examinados 498 bovinos entre fêmeas e machos. Os membros pélvicos foram mais acometidos, tanto nas fêmeas quanto nos machos. Foram diagnosticadas 629 lesões nas fêmeas, sendo as mais frequentes pododermatite séptica, deformações ungulares, pododermatite da sobreunha e dermatite digital. Nos machos diagnosticou-se 285 lesões e as mais frequentes foram pododermatite séptica, deformações ungulares e abrasão de talão. Conclui-se que erros de manejo associados às condições inadequadas das instalações foram fatores que contribuíram para a ocorrência de enfermidades podais em bovinos de corte nas fazendas estudadas; as características ambientais favoreceram o desenvolvimento das lesões; as associações de lesões foram mais prevalentes do que as simples, sendo diagnosticadas em animais em todas as fazendas estudadas; o diagnóstico precoce a campo não era realizado, o que contribuiu para aumentar a gravidade e a diversificação das afecções podais diagnosticadas.

TERMOS DE INDEXAÇÃO: Epidemiologia, afecções podais, bovinos de corte, Pará, claudicação, pododermatite, Amazônia, clínica.

\section{INTRODUÇÃO}

As enfermidades podais são consideradas as maiores causas de dor e desconforto na espécie bovina e acarretam consideráveis prejuízos econômicos, de acordo com trabalhos realizados em bovinos leiteiros em diferentes estados brasileiros como: Mato Grosso do Sul (Martins et al. 2002), Goiás (Silva 1997) e Minas Gerais (Ferreira et al. 2004, Souza et al. 2006).

Apesar da importância do assunto, muitos relatos abordam o tema de forma mais direcionada a bovinos leiteiros criados de forma intensiva ou semi-intesiva, porém, pouco aplicável a realidade do sistema extensivo de produção, deixando uma lacuna nas informações epidemiológicas das enfermidades podais em rebanhos de corte manejados extensivamente. Além disso, não se devem desprezar os índices crescentes de enfermidades digitais em rebanhos mistos e de criação extensiva (Silveira et al. 2008, Silveira et al. 2010, Silveira et al. 2011).

Silveira et al. (2009), no estado do Pará, relataram enfermidades podais em bovinos manejados em regime extensivo de produção. Porém, diferentemente do que está sendo proposto neste trabalho, esses estudos estavam diretamente relacionados a bovinos leiteiros. Apesar da importância dessas afecções, sua prevalência e epidemiologia em bovinos de corte manejados extensivamente no estado do Pará não é conhecida. Por isso, este trabalho registra alguns fatores epidemiológicos, classifica e caracteriza clinicamente as principais afecções podais diagnosticadas em bovinos de corte manejados extensivamente na região sudeste do estado do Pará.

\section{MATERIAL E MÉTODOS}

Este estudo foi realizado em 12 propriedades de criação de gado de corte localizadas na mesorregião sudeste do estado do Pará e abrangeu os municípios de Piçarra, Xinguara, Curionópolis, Rondon do Pará e Paragominas. Sendo que nas 12 fazendas realizou-se o estudo epidemiológico e em nove o estudo epidemiológico e exame clínico dos animais para o diagnóstico das enfermidades podais. Para o estudo epidemiológico foram avaliados aspectos relacionados às características dos centros de manejo (condições físicas da infraestrutura, manutenção e higiene), ao manejo dos animais, às vias de acesso aos centros de manejo (material utilizado na pavimentação), ao tipo de transporte, às características das pastagens (manutenção, topografia, presença de pedras e tronco de árvores), à prática de sodomia entre os animais, às medidas preventivas utilizadas, à assistência técnica, além da aplicação de um questionário para indicar fatores precursores de enfermidades podais. Foram examinados os dígitos de 498 bovinos que apresentavam claudicação (de graus variados) ou com lesões visíveis nos dígitos. Esses animais foram selecionados por tratadores e estavam separados do rebanho para tratamento. Do total de bovinos avaliados, 307 eram fêmeas e 191 eram machos. 0 exame clínico dos dígitos foi realizado após a devida contenção dos animais e após a retirada de toda a matéria orgânica aderida aos cascos e a lavagem com água e sabão. Em seguida, os dígitos foram avaliados pela inspeção, palpação direta e indireta, e percussão de acordo com o estabelecido por Dirksen et al. (2008). As afecções foram classificadas conforme descrições apresentadas anteriormente (Weaver et al. 1981, Greenough et al. 1983, Hull et al. 1993, Venter \& Van Amstel 1994).

\section{RESULTADOS}

\section{Aspectos epidemiológicos}

Os bovinos de aptidão para corte das propriedades estudadas eram da raça Nelore, na maior parte, e mestiços de Nelore com raças taurinas, com idades que variavam de 2 a 15 anos para as fêmeas e de 2 a 4 anos para os machos. Estes animais, em todas as propriedades, eram criados em regime extensivo de produção em pastagens de Brachiaria sp., com suplementação mineral e água a vontade.

Nas fazendas estudadas os currais não possuíam cobertura, o piso era de chão batido ou cascalhos, sem drenagem adequada. As seringas possuíam pisos calçados com pedras; as rampas dos embarcadores e de acesso à balança possuíam piso recoberto de concreto e/ou pedras pontiagudas. A falta de manutenção das instalações também foi observada, como pregos salientes, peças de madeira solta e/ou pontiagudas, aberturas laterais nas seringas, troncos de contenção com travas antiderrapantes desgastadas com exposição de ferragens e tábuas laterais com quinas salientes (Fig.1). Além disso, era comum dentro das instalações a presença de objetos metálicos, vidros, sucatas e o acúmulo de fezes e urina, que formavam, junto às águas das chuvas, poças de lama.

As vias de condução dos bovinos do pasto aos currais eram pavimentadas com cascalho. Os bovinos quando submetidos a manejos de vacinação e reprodução percorriam longas distâncias até os currais, com perímetros de até seis quilômetros. Em 16,7\% das propriedades (2/12), era realizado IATF (Inseminação Artificial em Tempo Fixo) e as vacas eram encaminhadas aos centros de manejo repetidas vezes, em intervalos pequenos. Em 58,3\% das propriedades (7/12), foi relatado o transporte a pé de bovinos entre fazendas distintas e este manejo era realizado com frequência em grandes lotes de animais, em estradas de cascalho e de asfalto, com duração de vários dias (Fig.2). Segundo os tratadores era comum o aparecimento de animais claudicacantes após estes manejos. 

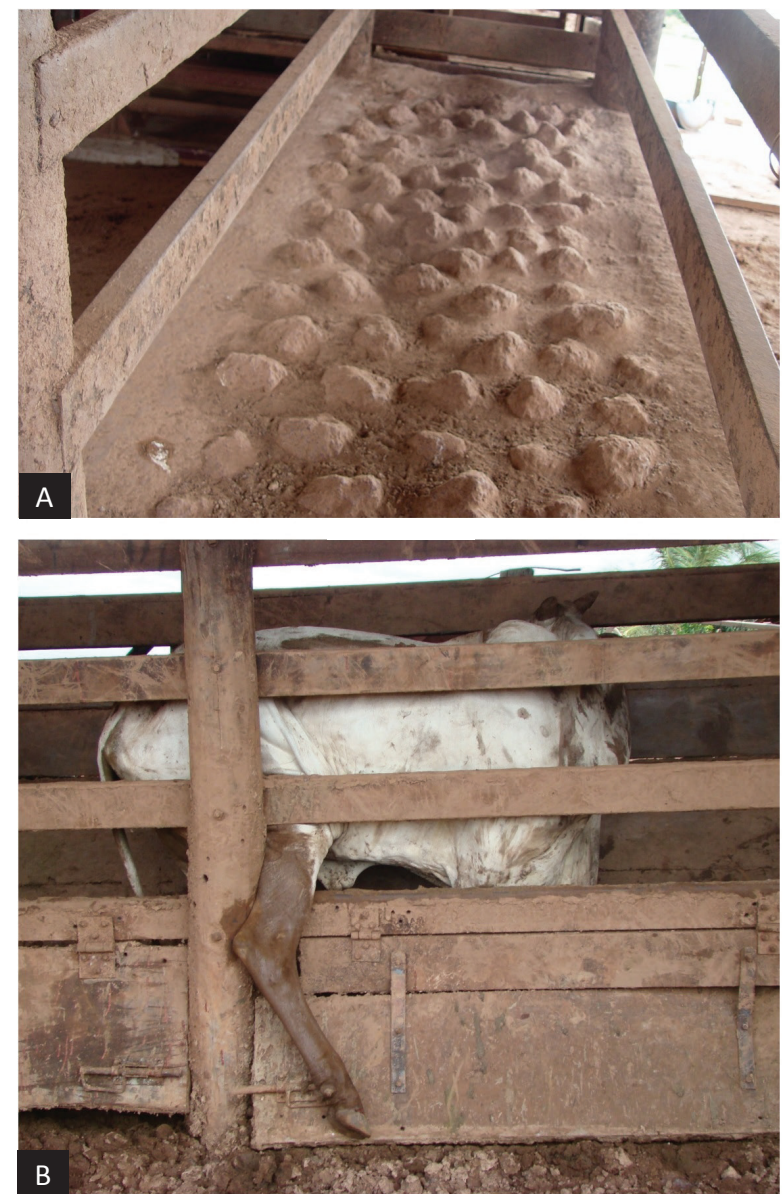

Fig.1. Características indesejáveis em instalações de bovinos de corte criados na região sudeste do Pará. (A) Rampa de concreto para acesso à balança com piso irregular. (B) Aberturas largas nas laterais das seringas, o que permite que os animais, durante o manejo, passem os membros e exponha os dígitos e sobreunhas às ferragens, o que favorece traumatismos.

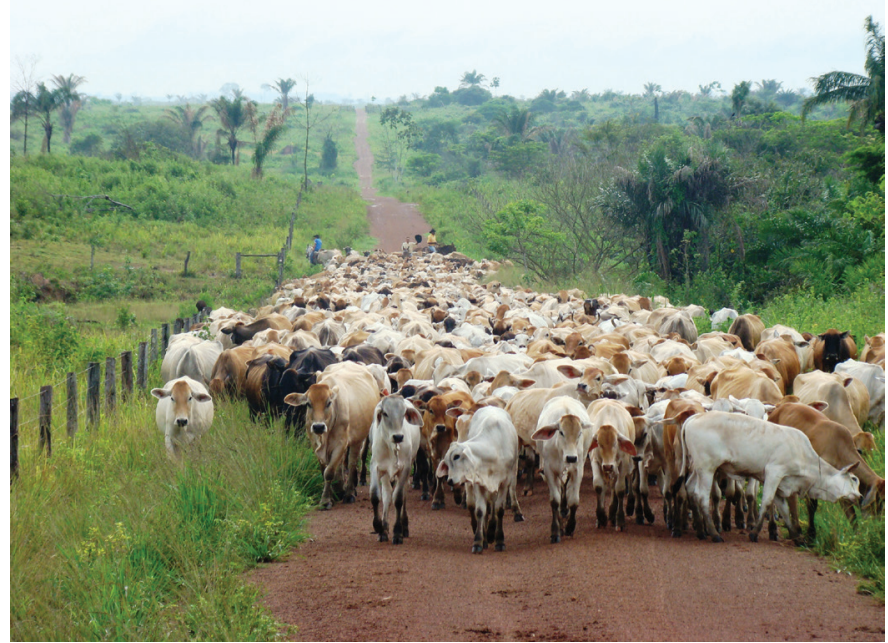

Fig.2. Manejo animal inadequado de bovinos de corte criados na região sudeste do Pará. Lote de fêmeas e bezerros sendo conduzidos ao centro de manejo, percorrendo longas distâncias por vias de acesso pavimentadas com cascalho, para procedimentos reprodutivos.
Nos currais, na tentativa de acelerar os procedimentos, os bovinos eram estimulados pelos tratadores com choques elétricos, fortes pancadas e objetos pontiagudos o que aumentava o estresse e agressividade dos animais.

A topografia dos terrenos era plana em 33,3\% (4/12) das propriedades e com áreas de relevo inclinado em $66,7 \%$ (8/12) e com pedras. Em 16,7\% (2/12) das propriedades havia áreas alagadas nas pastagens, principalmente durante o período chuvoso. Em todas as propriedades a manutenção das pastagens era deficiente e apresentavam plantas invasoras que formavam juquira. Em 91,7\% (11/12) das fazendas havia piquetes reformados em áreas de mata secundária com troncos e tocos de árvores.

Distúrbios de comportamento entre bovinos, como o homossexual (sodomia) foi relatado em todas as propriedades estudadas, principalmente em lotes de animais mestiços de Europeu-Nelore não castrados (Fig.3). Nenhuma das fazendas adotava medidas profiláticas relacionadas às afecções podais. Porém, 16,7\% (2/12) das propriedades utilizavam pedilúvio, com solução de formol e sulfato de cobre, para auxiliar na recuperação de animais tratados. Nessas fazendas, os procedimentos terapêuticos, com
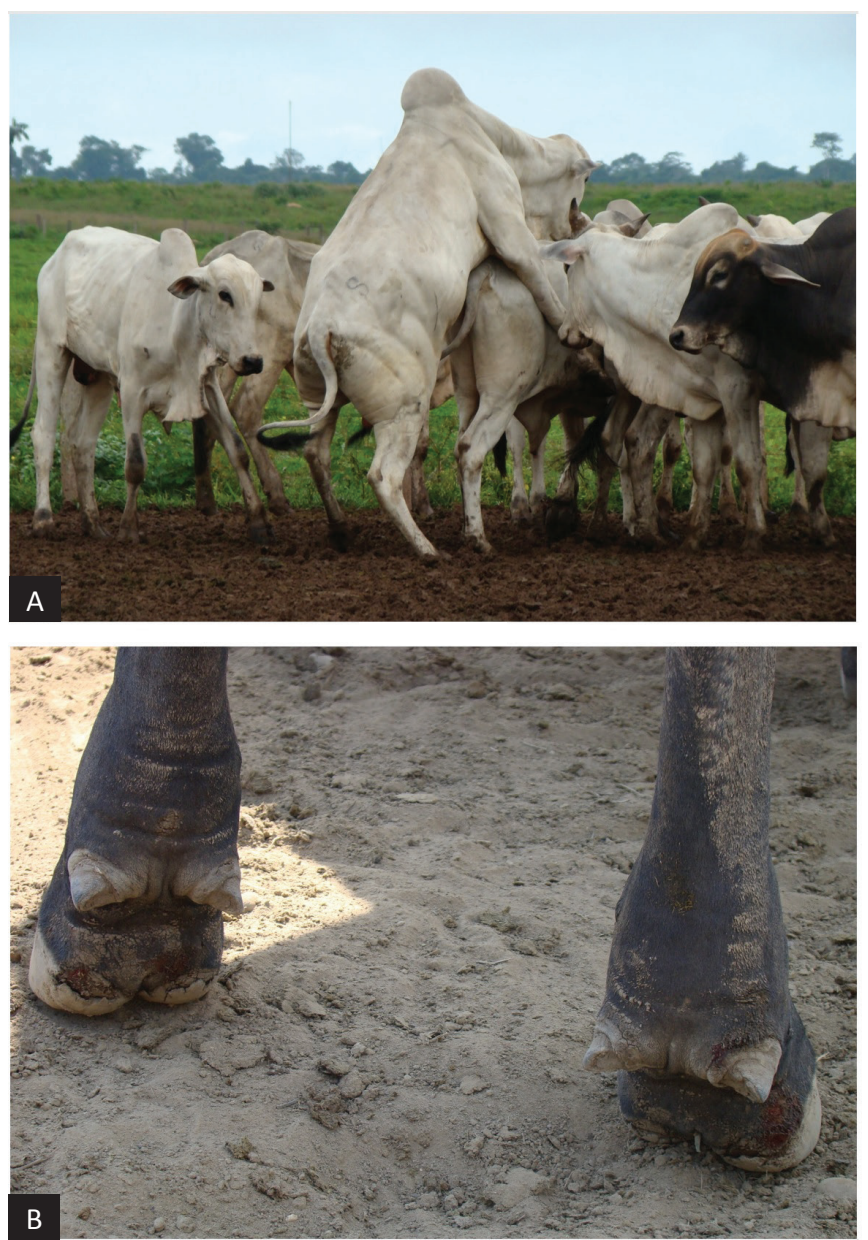

Fig.3. Abrasão de talão. (A) Bovinos machos, Nelore, não castrado realizando sodomia. (B) Erosões no tecido córneo dos talões, na base da sobreunha, quartela e coroa dos membros pélvicos em consequência da sodomia. 
amputação de dígitos, em muitos casos, eram realizados pelos tratadores sem critérios técnicos e orientação veterinária. Em 41,6\% das fazendas estudadas (5/12), os proprietários mantinham relação de compra e venda de bovinos e não adotavam medidas de prevenção quanto a alterações de casco.

\section{Características clínicas}

De um total de 62.950 bovinos, foi realizado o exame clínico dos dígitos em $0,79 \%$ destes (498 animais). A quantidade de bovinos avaliados foi de $0,09 \%$ a $4,8 \%$ entre as propriedades. As lesões podais diagnosticadas nesse estudo estão apresentadas no Quadro 1. Foram diagnosticadas 629 lesões nas fêmeas, sendo as mais frequentes pododermatite séptica, deformações ungulares, pododermatite da sobreunha e dermatite digital (Fig.4 e 5). Nos machos diagnosticou-se 285 lesões e as mais frequentes foram pododermatite séptica, deformações ungulares e abrasão de talão (Fig.3.B). Em todas as fazendas estudadas observaram-se animais com afecções podais, sendo que a maioria apresentava associações de lesões. Os animais acometidos apresentavam claudicação de graus variados, escore corporal ruim, na maioria, alterações de postura e as fêmeas vazias com anestro prolongado.

No Quadro 2 encontra-se o número e a distribuição das lesões nos membros e dígitos acometidos em fêmeas e machos, respectivamente. Verificou-se que os membros pélvicos foram os mais acometidos, tanto nas fêmeas com 465 lesões $(73,93 \%)$ quanto nos machos com 232 lesões $(81,4 \%)$. Em relação à distribuição das lesões nos dígitos, verifica-se que nos membros torácicos, predominaram, tanto nas fêmeas quanto nos machos, as lesões nas unhas mediais $(54,88 \%$ e $50,94 \%$, respectivamente). Nos membros pélvicos, nas fêmeas, as unhas laterais e mediais na mesma proporção $(42,8 \%$ e $42,2 \%$, respectivamente) e nos machos predominaram as lesões nas unhas laterais $(67,24 \%)$. As lesões localizadas nas sobreunhas foram observadas em maior quantidade, tanto nos machos quanto nas fêmeas, nas sobreunhas laterais dos membros pélvicos com $4,3 \%$ nos machos e $4,8 \%$ nas fêmeas.

0 espaço interdigital foi mais afetado nas fêmeas, tanto nos membros torácicos com $9,15 \%$ quanto nos membros pélvicos com $6,5 \%$ das lesões. Nos machos essa região do dígito foi bem menos afetada com 1,89\% nos membros torácicos e $1,73 \%$ nos membros pélvicos.

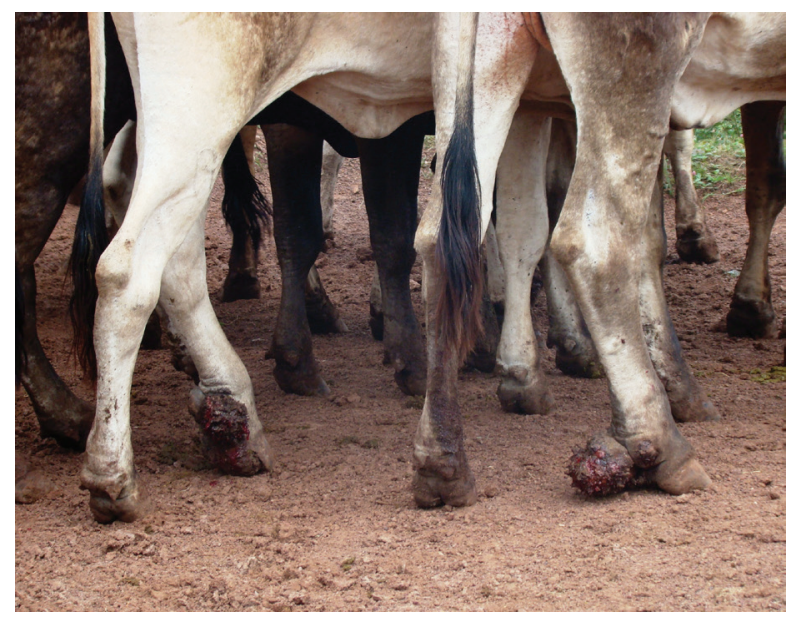

Fig.4. Pododermatite da sobreunha. Bovinos com perda de tecido córneo e proliferação acentuada de tecido de granulação nas sobreunhas dos membros pélvicos.

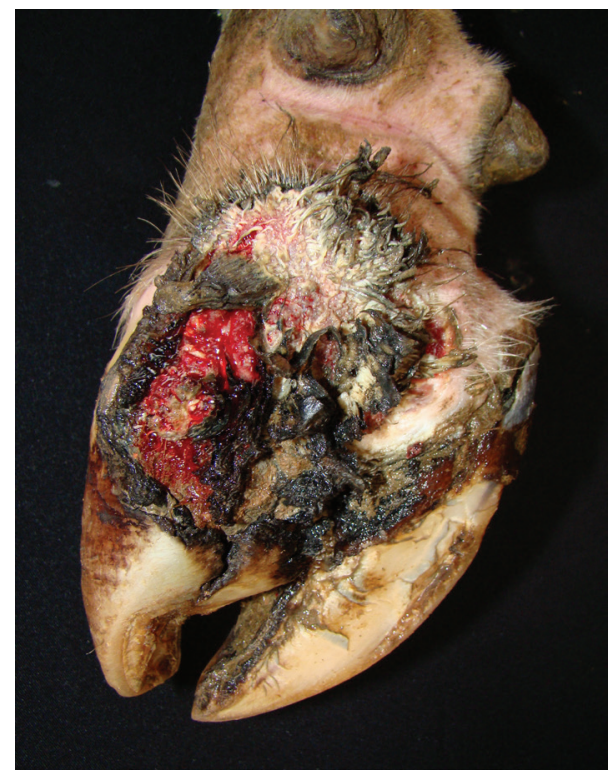

Fig.5. Dermatite digital. Perda de tecido córneo dos talões, sola e muralha abaxial do dígito com presença de pelos longos e espículas de cor variando de enegrecida a branca.

Quadro 1. Número e porcentagem de animais examinados e lesões podais diagnosticadas em bovinos de corte em nove fazendas localizadas na mesorregião sudeste do estado do Pará

\begin{tabular}{|c|c|c|c|c|c|c|c|c|c|c|c|c|c|c|c|c|c|}
\hline \multirow{2}{*}{ Propriedades } & \multirow{2}{*}{ Rebanho } & \multicolumn{2}{|c|}{ Animais avaliados } & \multicolumn{14}{|c|}{ Lesões diagnosticadas e $n^{\circ}$ de lesões } \\
\hline & & Quant. & $\%$ & PS & PSU & HI & DD & AT & DU & $\mathrm{FH}$ & FV & DI & DLB & SD & US & UP & ASA \\
\hline $\mathrm{A}$ & 11.000 & 151 & 1,37 & 172 & 38 & 38 & 20 & 10 & 7 & 3 & 2 & 2 & 2 & 1 & 1 & - & - \\
\hline B & 15.000 & 14 & 0,09 & 12 & - & - & - & - & 3 & 1 & - & - & - & 2 & - & 2 & - \\
\hline $\mathrm{C}$ & 4.000 & 18 & 0,45 & 13 & - & - & 2 & - & - & 6 & 3 & - & 4 & 4 & - & - & - \\
\hline $\mathrm{F}$ & 15.000 & 158 & 1,04 & 161 & 4 & 2 & - & 6 & 124 & 12 & 11 & 1 & 5 & - & 1 & 3 & - \\
\hline G & 10.000 & 89 & 0,89 & 53 & 4 & 1 & - & 22 & 29 & 4 & 19 & - & 1 & - & 1 & 2 & - \\
\hline $\mathrm{H}$ & 700 & 22 & 3,14 & 18 & 8 & 1 & - & 2 & 2 & - & - & - & - & - & - & - & - \\
\hline $\mathrm{J}$ & 3.000 & 12 & 0,40 & 12 & 1 & - & - & - & 4 & - & - & - & - & - & - & - & - \\
\hline $\mathrm{L}$ & 250 & 12 & 4,80 & 12 & 1 & 2 & - & - & 2 & - & 1 & - & - & - & - & - & 1 \\
\hline M & 4.000 & 22 & 0,52 & 21 & - & - & - & - & 10 & - & - & - & - & 1 & - & - & 1 \\
\hline TOTAL & 62.950 & 498 & 0,79 & 474 & 56 & 44 & 22 & 40 & 181 & 26 & 36 & 3 & 12 & 8 & 3 & 7 & 2 \\
\hline
\end{tabular}

PS = Pododermatite séptica, PSU = Pododermatite da sobreunha, HI = Hiperplasia interdigital, DD = Dermatite digital, AT = Abrasão de talão, DU = Deformações ungulares, FH = Fissura horizontal, FV = Fissura vertical, DI = Dermatite interdigital, DLB = Doença da linha branca, SD = Sola dupla, US = Úlcera de sola, UP = Úlcera de pinça, ASA = Artrite séptica da articulação interfalangeana distal. 
Quadro 2. Distribuição das lesões podais diagnosticadas em 307 fêmeas e 191 machos bovinos de corte criados na mesorregião sudeste do estado do Pará

\begin{tabular}{|c|c|c|c|c|c|c|c|c|}
\hline \multirow{3}{*}{ Localização } & \multicolumn{4}{|c|}{ Fêmeas } & \multicolumn{4}{|c|}{ Machos } \\
\hline & \multicolumn{2}{|c|}{$\mathrm{MT}^{*}$} & \multicolumn{2}{|c|}{$\mathrm{MP}^{* *}$} & \multicolumn{2}{|c|}{ MT } & \multicolumn{2}{|c|}{ MP } \\
\hline & Quant. & $\%$ & Quant. & $\%$ & Quant. & $\%$ & Quant. & $\%$ \\
\hline Unhas mediais & 90 & 54,88 & 197 & 42,20 & 27 & 50,94 & 58 & 25,00 \\
\hline Unhas laterais & 57 & 34,76 & 199 & 42,80 & 24 & 45,28 & 156 & 67,24 \\
\hline Espaço interdigital & 15 & 9,15 & 30 & 6,50 & 1 & 1,89 & 4 & 1,73 \\
\hline Sobre unhas mediais & 1 & 0,60 & 17 & 3,70 & 1 & 1,89 & 4 & 1,73 \\
\hline Sobre unhas laterais & 1 & 0,60 & 22 & 4,80 & - & - & 10 & 4,30 \\
\hline TOTAL & 164 & 100 & 465 & 100 & 53 & 100 & 232 & 100 \\
\hline
\end{tabular}

* Membros torácicos, ${ }^{* *}$ Membros pélvicos.

\section{DISCUSSÃO}

Estudos realizados em bovinos leiteiros mostram que as enfermidades de casco são determinadas por fatores predisponentes relacionados a aspectos ambientais e/ou decorrentes do manejo inadequado (Silva et al. 2001, Silveira et al. 2009, Albuquerque et al. 2009). Pisos de concreto e pedras pontiagudas, exposição de ferragens, tábuas laterais com quinas salientes e estresse dos animais dentro das instalações são fatores que agregam condições favoráveis a acidentes que podem iniciar lesões na pele ou no tecido córneo do casco. Além disso, os índices pluviométricos consideráveis da região estudada (Oliveira et al. 2004), associados a presença de cascalho nos currais, favorece a formação de lama. De acordo com Silva et al. (2001), a higiene precária com acúmulo de material orgânico e elevada umidade são fatores imprescindíveis na gênese das afecções podais. Nesse sentido, a fragilidade do tecido do casco associada à utilização de cascalho pode elevar significativamente a ocorrência de problemas podais (Allenstein 1981, Bergsten 1994, Molina et al. 1999, Dias \& Marques 2003).

Observou-se neste estudo que quando deixados à vontade nas vias de acesso, os animais posicionavam-se em fila e evitavam o cascalho. Tal observação está de acordo com relatos de Clackson \& Ward (1991). Porém, quando estimulados, obrigatoriamente, caminhavam sobre o cascalho, o que provavelmente favorecia as lesões por traumatismos, principalmente nos animais submetidos a longas caminhadas para a realização de manejo reprodutivo ou transferidos a pé entre fazendas. Albuquerque et al. (2009) mostraram que caminhadas forçadas sobre concreto, somado à umidade foram importantes para os problemas digitais em vacas confinadas.

Piquetes com presença de troncos e galhos de árvores, solos pedregosos e áreas de relevo inclinado observadas com frequência no presente estudo, são fatores ambientais importantes associados à claudicação em bovinos, já relatados no estado do Pará (Silveira et al. 2009) e em outras regiões do País (Silva et al. 2001, Ferreira et al. 2004) e provavelmente também atuaram nos bovinos do presente estudo. Segundo Malafaia et al. (2011), no estado do Pará, muitas pastagens foram formadas após intenso e indiscriminado desmatamento, resultando na degradação dos solos e a grande incidência de tocos e troncos, que atuam como obstáculos naturais à locomoção dos animais.

Em nenhuma das propriedades estudadas instituía-se medidas profiláticas relacionadas às afecções podais e nas propriedades que realizavam o tratamento, esse era realizado de forma empírica. Vários estudos comprovam que para o controle das enfermidades podais faz-se necessária a adoção de diversas medidas terapêuticas e profiláticas, entre essas destacam-se: higiene das instalações, exames periódicos no rebanho, quarentena de animais, uso correto do pedilúvio, redução da distância percorrida dos piquetes até o centro de manejo e esterilização do material de casqueamento (Bergsten 1997, Dias \& Marques 2003, Nicoletti 2004).

Segundo Dirksen et al. (2008), para um exame minucioso dos dígitos e correto diagnóstico das enfermidades podais é imprescindível a contenção adequada dos animais. Os cascos devem ser limpos minuciosamente com água, sabão e escova. Porém, em fazendas de bovinos de corte manejados extensivamente, esse procedimento muitas vezes torna-se inviável devido à indisponibilidade de mão de obra, às inadequações das instalações que comprometem a contenção individual dos animais, ao grande número de animais e ao temperamento hostil de algumas raças. Por isso, de um total de 62.950 bovinos, apenas $498(0,79 \%)$ foram submetidos ao exame clínico neste estudo e nas fazendas o número de animais examinados variou de 0,09 a 4,8\%. Esse número subestima a realidade e não representa a totalidade de animais enfermos, uma vez que nesse estudo foram avaliados somente animais que estavam separados para tratamento. Muito provavelmente, animais com lesões iniciais, sem claudicação evidente, não foram identificados e, portanto, não avaliados.

Nas fêmeas, $73,93 \%$ das lesões ocorreram nos membros pélvicos e $26,07 \%$ nos membros torácicos. Resultados próximos do que foi verificado em gado de leite por Albuquerque et al. (2009), que encontraram 69,3\% das lesões nos membros pélvicos e 30,7\% nos membros torácicos. Martins et al. (2002) e Graça et al. (2006), também chegaram a resultados que comprovam a hipótese das afecções podais ocorrerem com maior frequência nos membros pélvicos. Entretanto, de acordo com nossos resultados, observamos que houve uma maior frequência de lesões nos membros pélvicos em machos (81,4\%) quando comparado com as fêmeas $(73,93 \%)$. Ressalta-se o comportamento de sodomia, como fator que, provavelmente, tenha influenciado nesse resultado, uma vez que em machos essa prática é muito mais comum. Segundo Malafaia et al. (2011), esse comportamento favorece as lesões de casco, pois os animais dominantes, que saltam repetidamente sobre os outros, lesionam os cascos posteriores e a intensa pressão do peso sobre as unhas origina danos à microcirculação do casco e consequentes hematomas na sola, seguidos por ulcerações nas mesmas. 
O estresse de sustentação de peso também difere entre as unhas, de forma que o casco medial suporta maior peso nos membros torácicos, enquanto que o casco lateral sustenta mais peso nos membros pélvicos, o que interfere positivamente na ocorrência de lesões nesses dígitos (Rebhun et al. 2000). Porém, o presente estudo mostra que nos membros pélvicos, em fêmeas, a incidência das lesões foi semelhante nas duas unhas.

Os resultados obtidos nesse estudo mostram que tanto nos machos quanto nas fêmeas a pododermatite séptica foi a enfermidade podal mais frequente, seguida pelas deformações ungulares. Outros estudos realizados em bovinos manejados a pasto no estado do Pará registraram doenças digitais em prevalências consideráveis. Silveira et al. (2009) identificaram a hiperplasia interdigital como a lesão mais frequente, seguida pela pododermatite séptica e pelo crescimento excessivo dos cascos. Em bovinos manejados semi-intensivamente em Goiás, identificou-se a dermatite digital, seguida pela dermatite verrucosa e pododermatite séptica (Silva et al. 2001). Ferreira et al. (2004) em bovinos leiteiros confinados em Belo Horizonte registrou como as lesões mais frequentes a abrasão de talão, doença da linha branca, hemorragia de sola e a dermatite digital.

Ao considerarmos as enfermidades podais que causam prejuízos nos rebanhos leiteiros, os resultados obtidos neste trabalho não foram diferentes. Entretanto, houve uma inversão de ordem nas enfermidades diagnosticadas. De acordo com Martins et al. (2002), isto é aceitável, quando se leva em consideração, principalmente, o caráter regionalizado que determinadas doenças adquirem, sendo sua ocorrência dependente do tipo de manejo (confinamento, criação a pasto ou ações preventivas), padrão genético dos rebanhos, manejo alimentar, bem como aspectos geográficos físicos e climáticos.

A pododermatite séptica e pododermatite da sobreunha são enfermidades de etiologia incerta ou secundárias (Borges 2007). Nos casos de pododermatite séptica, outras enfermidades do casco, como doença da linha branca, abrasão de talão, úlcera de sola, dermatite interdigital e dermatite digital podem ter contribuído, em algumas situações, para o estabelecimento do quadro, fato corroborado no presente estudo pelo diagnóstico dessas enfermidades em bovinos com lesões iniciais.

Embora o tempo de evolução das lesões seja desconhecido, as características clínicas indicavam processos avançados e em muitos casos, diagnosticou-se associações de lesões. Isso pode estar relacionado às condições predisponentes, à ausência de práticas preventivas, além do desconhecimento do produtor acerca das lesões e condutas a serem adotadas no controle. Neste estudo constatou-se, que além da influência dos fatores já citados, o diagnóstico precoce a campo e tratamento de lesões iniciais não era realizado, o que certamente contribuiu para aumentar a gravidade e diversificação das afecções podais diagnosticadas. Para Shearer (1998), o diagnóstico precoce, associado a tratamentos apropriados, minimizam as perdas econômicas e reduzem o sofrimento do animal, além de serem mais eficazes.

Diagnosticou-se pododermatite da sobreunha em fêmeas e machos. De acordo com Borges (2007), esta seria uma enfermidade não frequente. Em consonância com esse autor, no que diz respeito às causas, a observação de pastos sujos recém-desmatados, com muitos tocos foi frequente nas propriedades estudadas. Outras possíveis causas, observadas nesse estudo, foram aberturas laterais nas seringas, troncos de contenção com travas antiderrapantes desgastadas com exposição de ferragens e tábuas laterais com quinas salientes.

A dermatite digital e a dermatite interdigital foram diagnosticadas em três propriedades estudadas, onde os fazendeiros mantinham relação de compra e venda de animais e não adotavam critérios de biosseguridade com relação às doenças de casco. Segundo Bergsten (1997) e Cruz et al. (2001), essas enfermidades são comuns em animais mantidos em ambientes de confinamento, mas as características epidemiológicas observadas nas fazendas estudadas podem justificar a ocorrência no presente estudo. Bergsten (1997) e Silva (1998) alertam para a importância do exame específico dos cascos e a adoção da quarentena, a fim de que não sejam introduzidos animais portadores de problemas podais no criatório. Isso pode ser importante na proliferação de enfermidades podais entre rebanhos de bovinos de corte no estado do Pará, agravado pela intensa movimentação de gado entre fazendas.

Nesse contexto, é necessário enfatizar que algumas atitudes comuns no manejo com os bovinos são perfeitamente evitáveis e que podem contribuir para a menor ocorrência de enfermidades podais nas propriedades estudadas como, evitar o estresse nos centros de manejo e a condução forçada do gado por longas distâncias em pisos traumatizantes. Além disso, manter as instalações em boas condições físicas, evitar o uso de cascalho no piso das instalações e nas vias de acesso e associar essas medidas ao diagnóstico precoce das enfermidades podais e a tratamentos apropriados à realidade de cada fazenda. Porém, é importante ressaltar que, devido às grandes extensões das fazendas de bovinos de corte no estado do Pará, é inevitável a utilização de áreas com solos pedregosos e a presença de troncos e tocos de árvores por vários anos em áreas destinadas a pastagens para alimentação dos bovinos. Por isso, objetivando soluções viáveis que contribuam para o bem estar dos animais deve-se adotar estratégias de manejo e de biossegurança que possam refletir positivamente na produtividade e sanidade do rebanho, sempre associando à realidade de cada região.

\section{CONCLUSÕES}

Erros de manejo associados às condições inadequadas das instalações foram fatores que contribuíram para a ocorrência de enfermidades podais em bovinos de corte nas fazendas estudadas.

As características ambientais das fazendas estudadas favoreceram o desenvolvimento das lesões.

As lesões mais prevalentes tanto nas fêmeas quanto nos machos foram a pododermatite séptica, seguida pelas deformações ungulares.

Nas propriedades estudadas verificou-se a ausência de medidas de controle e profilaxia com relação às afecções podais.

0 diagnóstico precoce a campo não era realizado, o que provavelmente contribuiu para aumentar a gravidade e a diversificação das afecções podais diagnosticadas.

As enfermidades podais em gado de corte na região sudeste do estado do Pará são subestimadas, devido às dificuldades no manejo de se identificar animais com lesões iniciais. Portanto, os índices podem ser bem maiores do que os que foram encontrados nesse estudo. 


\section{REFERÊNCIAS}

Albuquerque P.I., Ximenes F.H.B., Moscardini A.C.R., Gouvêa L.V., Mota A.L.A.A., Godoy R.F. \& Borges J.R.J. 2009. Caracterização das afecções podais em rebanho de gado holandês confinado. Ciênc. Anim. Bras. 1 (Supl. 1):46-52.

Allenstein L.C. 1981. Lameness of cattle. Can. Vet. J. 22(3):65-67. PMid:7284947.

Bergsten C. 1994. Haemorrhages of the sole horn of dairy cows as a retrospective indicator of laminitis: an epidemiological study. Acta Vet. Scand. 35(1):55-66. PMid:8209821.

Bergsten C. 1997. Infectious diseases of the digits, p.89-100. In: Greenough P.R. (Ed.), Lameness in Cattle. 3rd ed. W.B. Saunders, Philadelphia.

Borges J.R.J. 2007. Doenças digitais dos bovinos, p.499-500. In: Riet-Correa F., Schild A.L., Lemos R.A.A., Borges J.R.J. (Eds), Doenças de Ruminantes e Equídeos. $3^{a}$ ed. Pallotti, Santa Maria.

Clackson D.A. \& Ward W.R. 1991. Farm tracks, stockman's herding and lameness in dairy cattle. Vet. Rec. 129(23):511-512. PMid:1785169.

Cruz C., Driemeier D., Cerva C. \& Corbellini L.G. 2001. Bovine digital dermatitis in southern Brazil. Vet. Rec. 148(18):576-577. http://dx.doi.org/10.1136/ vr.148.18.576. PMid:11370885.

Dias R.S. \& Marques Jr A.P. 2003. Atlas: casco em bovinos. $2^{\text {a }}$ ed. Lemos Editorial, São Paulo.

Dirksen G., Gründer H. \& Stöber M. 2008. Exame clínico dos bovinos. 3aㅡ ed. Guanabara Koogan, Rio de Janeiro.

Ferreira P.M., Leite R.C., Carvalho A.U., Facury Filho E.J., Souza R.C. \& Ferreira M.G. 2004. Custo e resultados do tratamento de sequelas de laminite bovina: relato de 112 casos em vacas em lactação no sistema free-stall. Arq. Bras. Med. Vet. Zootec. 56(5):589-594. http://dx.doi.org/10.1590/ S0102-09352004000500004.

Graça F.A.S., Alves P.A., Moura Jr C.C.S. \& Santos Jr J.B. 2006. Evaluation of 49 animals with a history of lameness, treated on a dairy farm in the municipality of Rio das Flores, Rio de Janeiro/Brazil. Annals International Symposium on Lameness in Ruminants. Uruguay, p.80-81.

Greenough P.R., McCallum F.J. \& Weaver A.D. 1983. Les boiteries des bovins. 3 ed. Du Point Veterinaire, Paris.

Hull B.L., Weaver A.D., Koenig G.J., Welker B., Rings D.M., St Jean G., Crawford W.H., Tulleners E. \& Ames N.K. 1993. Diseases of the musculo-skeletal system, p.864-881. In: Howard J.L. (Ed.), Current Veterinary Therapy: food animal practice. 3 rd ed. W.B. Saunders, Philadelphia.

Malafaia P., Barbosa J.D., Tokarnia C.H. \& Oliveira C.M.C. 2011. Distúrbios comportamentais em ruminantes não associados a doenças: origem, significado e importância. Pesq. Vet. Bras. 31(9):781-790. http://dx.doi. org/10.1590/S0100-736X2011000900010.

Martins C.F., Sarti E., Busato I., Pires P.P., Fiori C.H., Moreira C., Soares K., Betini B. \& Velasquez M. 2002. Prevalência e classificação das afecções podais em vacas lactantes na bacia leiteira de Campo Grande (capital) e municípios arredores, MS. Ensaios Ciênc. 6(2):113-137.

Molina L.R., Carvalho A.U., Facury Filho E.J., Ferreira P.M. \& Ferreira V.C.P. 1999. Prevalência e classificação das afecções podais em vacas lactantes na bacia leiteira de Belo Horizonte. Arq. Bras. Med. Vet. Zootec. 51(2):149152. http://dx.doi.org/10.1590/S0102-09351999000200004.

Nicoletti J.L.M. 2004. Manual de podologia bovina. Editora Manole, São Paulo.

Oliveira L.L., Fontinhas R.L., Lima A.M.M. \& Lima R.J.S. 2004. Mapas dos parâmetros climatológicos do estado do Pará: umidade, temperatura e insolação, médias anuais. Anais Congresso Brasileiro de Metereologia, Fortaleza, CE, p.7.

Rebhun W.C., Guard C. \& Richards C.M. 2000. Doenças do gado leiteiro. Editora Roca, São Paulo.

Shearer J.K. 1998. Lameness of dairy cattle: Consequence and causes. Bov. Pract. 1(32):79-85.

Silva C.A. 1997. Identificação e isolamento de Dichelobacter nodosus e de Fusobacterium necrophorum de bovinos portadores de pododermatite, relações com a etiopatogenia, dados edafoclimáticos e avaliação do tratamento. Dissertação de Mestrado, Universidade Federal de Goiás, Goiânia. 81p.

Silva L.A.F. 1998. Haja casco para tanta doença. Revta Prod. 3(22):17-21.

Silva L.A.F., Silva L.M., Romani A.F., Rabelo R.E., Fioravanti M.C.S., Souza T.M. \& Silva C.A. 2001. Características clínicas e epidemiológicos das enfermidades podais em vacas lactantes do município de Orizona/GO. Ciênc. Anim. Bras. 2(2):119-126.

Silveira J.A.S., Albernaz T.T., Oliveira C.M., Duarte M.D. \& Barbosa J.D. 2009. Afecções podais em vacas da bacia leiteira de Rondon do Pará. Pesq. Vet. Bras. 29(11):905-909. http://dx.doi.org/10.1590/S0100-736X2009001100007.

Silveira J.A.S., Albernaz T.T., Sousa M.G.S., Campos K.F., Silva N.S., Oliveira C.M.C., Duarte M.D. \& Barbosa J.D. 2008. Prevalência e características clínicas das enfermidades podais diagnosticadas pela central de diagnóstico veterinário (CEDIVET), no estado do Pará, durante o período de 2000 a 2006. Anais Encontro Nacional de Diagnóstico Veterinário. Campo Grande, MS, p.79-80.

Silveira J.A.S., Oliveira C.M.C., Albernaz T.T., Silva N.S., Vinhote M.M.S., Lima D.H.S., Bomjardim H.A. \& Barbosa J.D. 2010. Dermatite digital em bovinos de corte e leite criados em regime extensivo no estado do Pará. Anais VI Encontro Nacional de Diagnóstico Veterinário (Endivet), Campo Grande, MS, p.112.

Silveira J.A.S., Silva N.S., Albernaz T.T., Bomjardim H.A., Andrade S.J.T., Oliveira C.M.C. \& Barbosa J.D. 2011. Afecções podais em bovinos associado à sodomia. Vet. Zootec. 18 (4, Supl. 3):294-297.

Souza R.C., Ferreira P.M., Molina L.R., Carvalho A.U. \& Facury Filho E.J. 2006. Perdas econômicas ocasionadas pelas enfermidades podais em vacas leiteiras confinadas em sistema free stall. Arq. Bras. Med. Vet. Zootec. 58(6):982-987. http://dx.doi.org/10.1590/S0102-09352006000600002.

Venter B.J. \& Van Amstel S.R. 1994. Fusobacterium necrophorum, Dichelobacter (Bacteroides) nodosus and Bacteroids spp. infections, p.1200-1228. In: Coetzer J.A.W., Thomson G.R. \& Tustin R.C. (Eds), Infectious Diseases of Livestock with Special Reference to Southern Africa. Oxford University Press, Cape Town.

Weaver A.D., Andersson L., De Laistre Banting A., Demerzis P.N., Knezevic P.F, Peterse D.J. \& Sankovic F. 1981. Review of disorders of the ruminant digit with proposal for anatomical and pathological terminology and recording. Vet. Rec. 108(6):117-120. http://dx.doi.org/10.1136/vr.108.6.117. PMid:7257157. 